\title{
INFLUENCE OF SODIUM INTAKE ON EXCHANGEABLE SODIUM IN NORMAL HUMAN SUBJECTS *
}

\author{
By PAUL I. JAGGER, $\dagger$ GERALD J. HINE, JOHN A. CARDARELLI, AND BELTON A. \\ BURROWS WITH THE TECHNICAL ASSISTANCE OF VALENTINE BIKERMAN \\ (From the Evans Memorial Department of Clinical Research, Massachusetts Memorial Hos- \\ pitals, the Radioisotope and Medical Services, Boston Veterans Administration Hos- \\ pital, and the Department of Medicine, Boston University School of Medicine, \\ Boston University Medical Center, Boston, Mass.)
}

(Submitted for publication November 19, 1962; accepted May 31, 1963)

Several methods for determining exchangeable sodium in human subjects by using the gammaray emitter $\mathrm{Na}^{22}$ (half-life 2.6 years) in conjunction with measurements of body radioactivity have previously been described (1-3). With these methods, it is possible to make repeated exchangeable sodium determinations over a period of several weeks or months after giving a single tracer dose of the radioisotope. Sodium metabolism can thus be studied in a way that has certain advantages over conventional metabolic balance techniques in that sodium losses from all sources are accounted for and the results obtained reflect specifically changes in the active sodium pool.

For the determination of exchangeable sodium, a 24- to 48-hour period is usually allowed for exchange of the tracer sodium with body sodium in adult subjects, but some observations have suggested that there is significant continuing exchange after this interval $(1,4-7)$. The fraction of body sodium not exchanged in 24 to 48 hours is estimated at $30 \%$ of total body sodium and is thought to consist mostly of sodium in bone (4, 5, 8-11). If these observations are correct, they would seriously limit the interpretation of longterm exchangeable sodium determinations after a single $\mathrm{Na}^{22}$ injection, for this slow exchange would result in a continually increasing calculated exchangeable sodium, and it would be difficult at any given time to determine how much of a measured increase in exchangeable sodium was due to the continuing internal exchange and how much

* Submitted in honor of Chester S. Keefer, M.D., and the Golden Anniversary of the Evans Memorial Department of Clinical Research, Boston, Mass. Published in part in abstract form: Clin. Res. 1959, 7, 283.

$\dagger$ Work done during tenure of a U. S. Public Health Service Postdoctoral Fellowship. Present address: U. S. Naval Hospital, San Diego, Calif. to an actual increase in body sodium. Furthermore, if our interest is in the active sodium pool, that is, that part of body sodium available for relatively rapid metabolic accommodations, it would be erroneous to represent this pool by an exchangeable sodium value which included sodium that had taken several days to equilibrate with the tracer.

In the present report, $\mathrm{Na}^{22}$ and a body radioactivity counter have been employed for repeated exchangeable sodium determinations in five normal individuals, each given widely varied amounts of sodium over extended periods. The influence of changes in sodium intake on and the contribution of slowly exchanging body sodium to such exchangeable sodium values were evaluated.

\section{METHODS}

Experimental procedure. Five healthy men varying in age from 23 to 40 received iv tracer doses of $\mathrm{Na}^{22}$ (10 to $15 \mu \mathrm{c}$ ). Three of the subjects (B.E., L.M., and P.J.) were taking fixed low-sodium diets at the time of the injection, and the other two (B.B. and J.C.) were taking their normal diets with a variable sodium content and later were placed on fixed low-sodium diets. In three of the subjects (P.J., B.B., and J.C.), the fixed lowsodium diet consisted of a liquid synthetic preparation that provided $2 \mathrm{mEq}$ of sodium per day or less. ${ }^{1}$ The low-sodium diet for the other two subjects (B.E. and L.M.) was a hospital low-sodium diet supplying an average of $20 \mathrm{mEq}$ of sodium per day. The period of fixed low-sodium intake was followed in each subject by a period of fixed relatively high-sodium intake. During the period of high intake, two of the subjects (P.J. and B.B.) took their daily sodium load of $200 \mathrm{mEq}$ orally in the first

${ }_{1}$ The major component of the diet for J.C. and B.B. was kindly supplied as Product 3060-1-A by Mead Johnson \& Co., Evansville, Ind. The synthetic diet for P.J. was generously furnished by Dr. Jacob Lemann, Jr.; its major constituents were soybean flour, corn oil, and glucose. 
TABLE I

Body weight; sodium intake, output, and serum concentration; serum and body $\mathrm{Na}^{22}$ values; and exchangeable sodium determinations in Subject P.J.

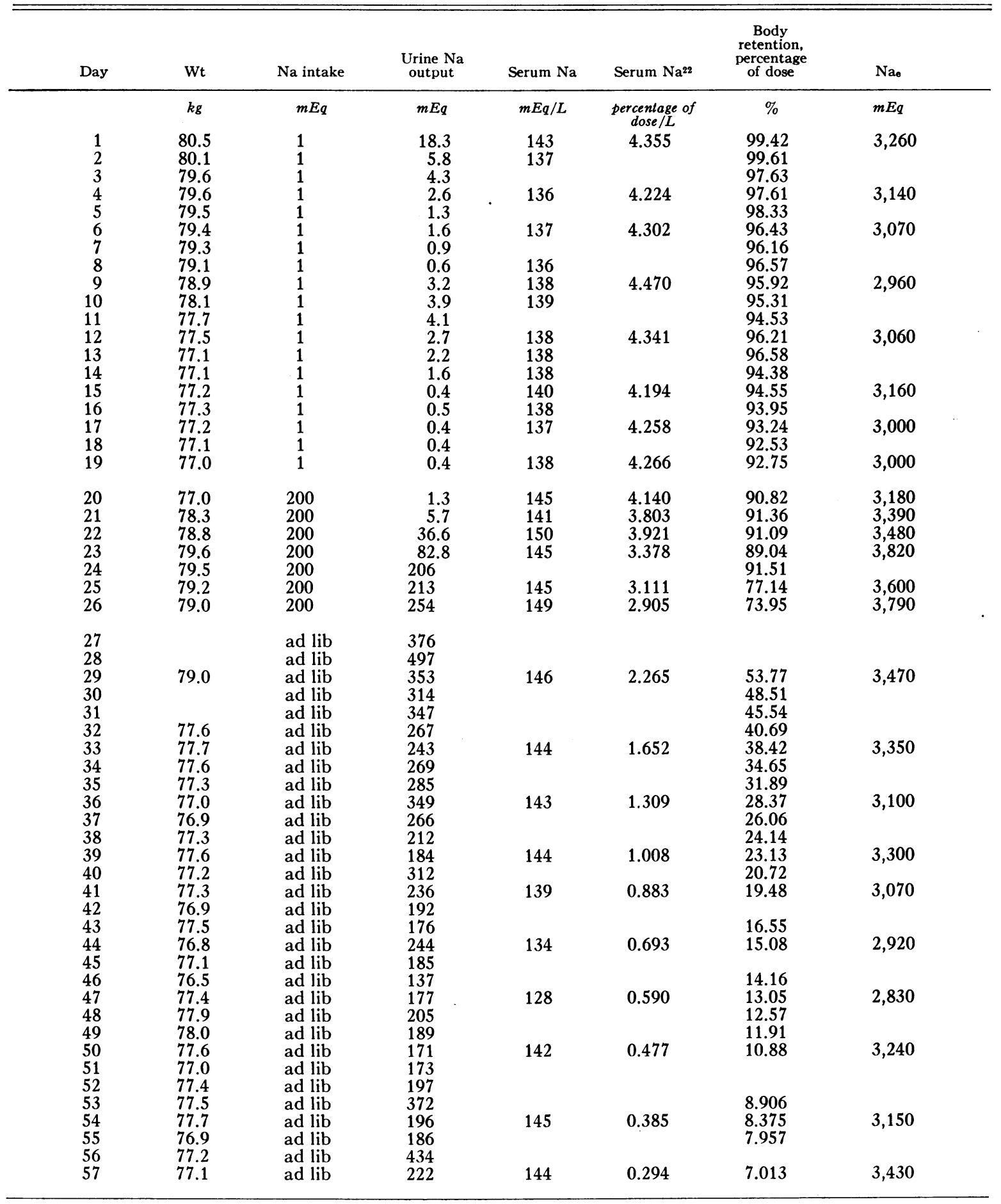




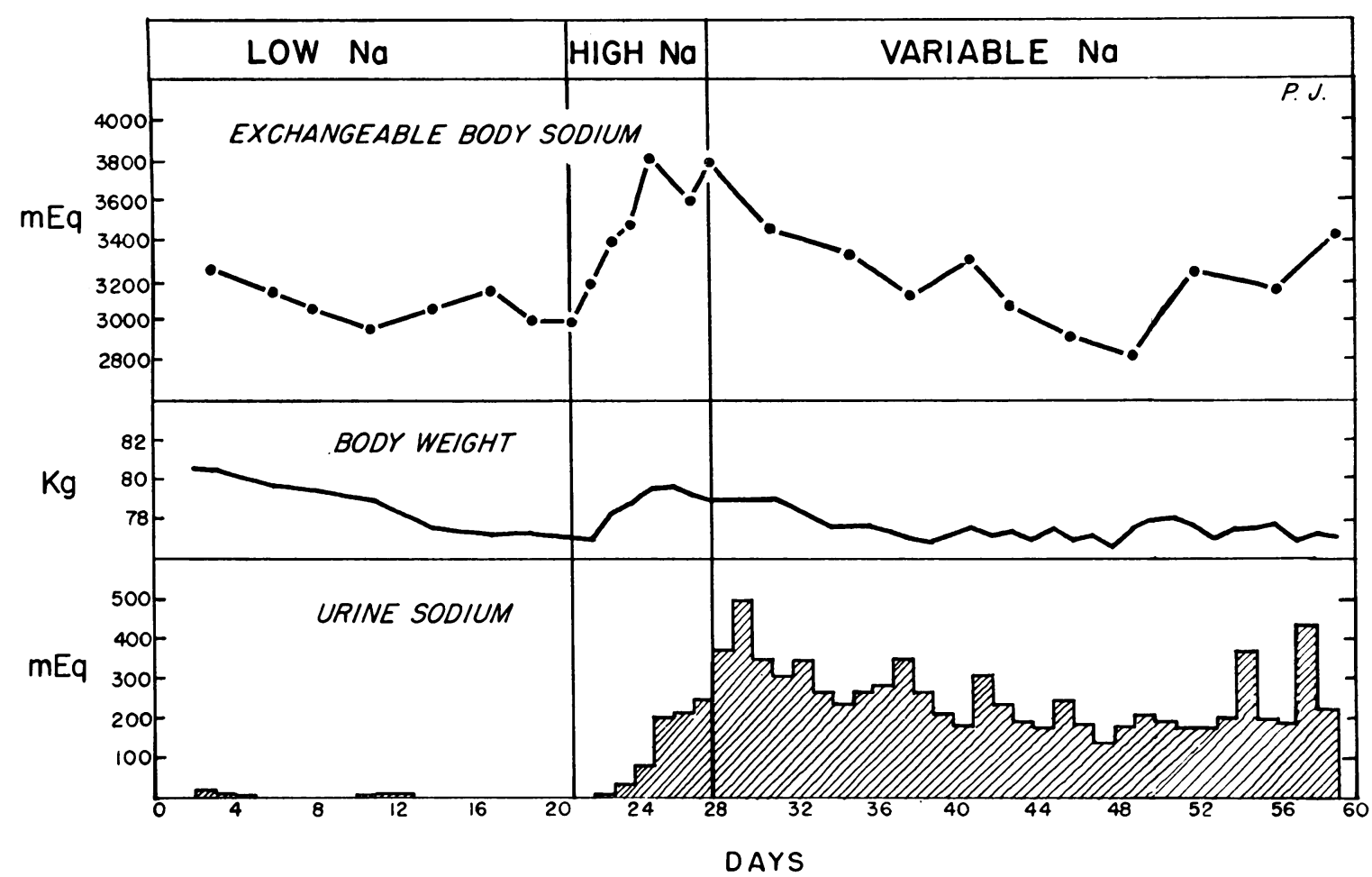

Fig. 1. Exchangeable sodium values, body weight, and urine sodium plotted against time. Salt loading in this subject was accomplished by the ingestion of $\mathrm{NaCl}$ tablets. At his own request, the subject was on a lowcalorie diet during the first two dietary periods. Note that his weight at the end of the study (day 59) was 3.5 $\mathrm{kg}$ less, but his exchangeable sodium was slightly higher. This suggests the loss of sodium-free tissues, presumably mainly fat.

8 to 10 hours of each 24 -hour period, and the other three (B.E., L.M., and J.C.) received their sodium load of 181 to $359 \mathrm{mEq}$ per day intravenously in the form of $5 \%$ saline solution in the first 2 hours of each 24-hour period. After the period of high-sodium intake, each subject resumed his normal diet and was followed for an additional period on a variable sodium intake.

A study day ran from one morning to the next and ended with the patient fasting. Urine was collected each day for determination of 24-hour urine sodium excretion. One subject (P.J.) also collected all stools during the periods of fixed low- and fixed high-sodium intakes, and pooled stool specimens were analyzed for sodium content after nitric acid digestion. Venous blood samples were drawn, and body radioactivity measurements were made at the end of the study day.

Body radioactivity measurements. Body radioactivity measurements were made with the subject seated in a contour chair beneath the open end of a shielded sodium iodide crystal 4 inches in diameter by 4 inches in height. The center of the crystal was placed $50 \mathrm{~cm}$ from the midline of the body. The details and efficiency of this counting arrangement have been described elsewhere (3). Separate measurements of the radioactivity of the knee and the posterior aspect of the head were made with smaller sodium iodide crystals. At the knee, the collima- tion for the crystal was such that the $\mathrm{Na}^{22}$ radioactivity measured came from a limited area composed mainly of the bony structures (5). At the posterior aspect of the head (lower occipital area), there was less collimation, and radioactivity from a wider area containing cerebrospinal fluid and brain tissue as well as bone was measured.

Sample measurements. The $\mathrm{Na}^{22}$ radioactivities of serum and urine samples were determined in a standard sodium iodide well-counter. In one study where $\mathrm{Na}^{24}$ was measured in the presence of $\mathrm{Na}^{22}$ (Subject B.E.), a differential pulse height analyzer was used. Chemical sodium concentration of samples was measured by flame photometry.

Calculations. Exchangeable sodium was derived from the retention of $\mathrm{Na}^{22}$ determined from body radioactivity measurements, serum $\mathrm{Na}^{22}$ concentrations, and serum concentration of stable sodium. The formula employed was: Exchangeable sodium $=$ body $N^{22}$ retention (per cent) $\times$ serum sodium concentration (milliequivalents per liter)/serum $\mathrm{Na}^{22}$ concentration (per cent per liter), where $\mathrm{Na}^{22}$ retention in the body and $\mathrm{Na}^{22}$ concentration in the serum are expressed as percentages of the initial dose.

The body counter was calibrated for each patient by equating the measurement at 24 hours with $\mathrm{Na}^{22}$ retention at that time as determined from urinary excretion. 


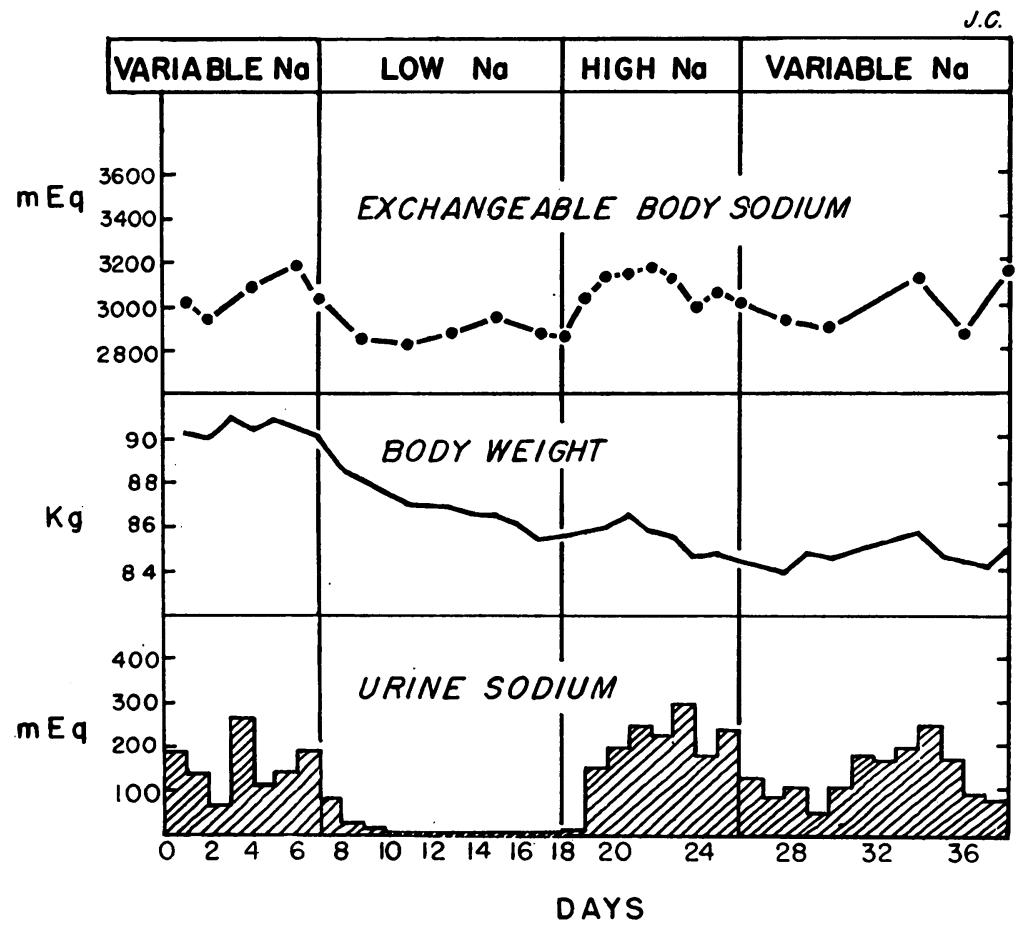

Fig. 2. Exchangeable SOdiUm, Body Weight, AND URINe SOdiUm PlotTed AGAINST TIME. Sodium supplementation during the period of high-sodium intake was administered intravenously. Exchangeable sodium during this period gradually increased to a peak value and then fell off to intermediate levels. The subject was also on a low-calorie reducing diet and lost a total of $5.3 \mathrm{~kg}$ over the course of the study without a decrease in the final exchangeable sodium values as compared to the initial ones.

Long-term $N a^{22}$ retention. In three subjects (P.J., B.B., and J.C.), measurements of body radioactivity due to $\mathrm{Na}^{22}$ were continued at intervals up to $2 \frac{1}{2}$ years after the initial injections with a more sensitive counting arrangement, consisting of an 8- $\times 4$-inch $\mathrm{NaI}$ (T1) crystal mounted in a steel room and connected to a multichannel pulse height analyzer. ${ }^{2}$ The purpose of these measurements was to determine the residual amount of the tracer dose of $\mathrm{Na}^{22}$ and the long-term turnover of this residual.

\section{RESULTS}

Exchangeable sodium. The three subjects who were taking a fixed low-sodium diet at the start of their studies (B.E., L.M., and P.J.) showed relatively constant values for exchangeable sodium throughout the period of fixed low-sodium intake (Figure 1, Table I). The two subjects who started their studies on regular diets (B.B. and J.C.) showed varying exchangeable sodium values as long as they remained on their regular diets,

\footnotetext{
${ }^{2}$ Radioactivity Center, Massachusetts Institute of Tech-
} nology, Cambridge, Mass. but when they changed to the fixed low-sodium diets, their exchangeable sodium values decreased for the first few days, and then also remained relatively constant (Figure 2 , Table II).

When each subject changed from a fixed lowsodium intake to a fixed high-sodium intake, there was a definite increase in his exchangeable sodium values. In two of the subjects (B.B. and J.C., Figure 2), there was a gradual increase to a peak value and then a fall-off to intermediate levels. In the other three subjects, there was no such clearly defined pattern. Despite this variation in exchangeable sodium values on the high-sodium intakes, there was a significant group increase in exchangeable sodium with increased sodium intake (Table III).

Values for exchangeable sodium during the final periods when the subjects resumed their normal diets again showed considerable variability; average values for this period were intermediate to the low- and high-sodium intake averages in three 
TABLE II

Body weight; sodium intake, output, and serum concentration; serum and body $\mathrm{Na}^{22}$ values; and exchangeable sodium determinations in Subject J.C.

\begin{tabular}{|c|c|c|c|c|c|c|c|}
\hline Day & Wt & $\mathrm{Na}$ intake & $\begin{array}{l}\text { Urine } \mathrm{Na} \\
\text { output }\end{array}$ & Serum Na & Serum $\mathrm{Na}^{22}$ & $\begin{array}{l}\text { Body } \\
\text { retention, } \\
\text { percentage } \\
\text { of dose }\end{array}$ & $\mathrm{Na}_{\mathrm{e}}$ \\
\hline \multirow{8}{*}{$\begin{array}{l}1 \\
2 \\
3 \\
4 \\
5 \\
6 \\
7\end{array}$} & $\mathrm{~kg}$ & $m E q$ & $m E q$ & $m E q / L$ & $\begin{array}{l}\text { percentage of } \\
\text { dose } / L\end{array}$ & $\%$ & $m E q$ \\
\hline & 90.2 & ad lib & 185 & 139 & 4.291 & 93.68 & 3,030 \\
\hline & 90.0 & ad lib & 136 & 136 & 4.141 & 89.80 & 2,950 \\
\hline & 90.8 & ad lib & 64.9 & & & 87.84 & \\
\hline & 90.4 & ad lib & 265 & 136 & 3.659 & 83.15 & 3,090 \\
\hline & 90.8 & ad lib & 114 & & & 79.33 & \\
\hline & 90.5 & ad lib & 143 & 142 & 3.410 & 76.26 & 3,180 \\
\hline & 90.0 & ad lib & 193 & 138 & 3.232 & 71.22 & 3,040 \\
\hline \multirow{11}{*}{$\begin{array}{r}8 \\
9 \\
10 \\
11 \\
12 \\
13 \\
14 \\
15 \\
16 \\
17 \\
18\end{array}$} & 88.5 & 1 & 79.5 & & & 69.72 & \\
\hline & 88.0 & 1 & 24.8 & 139 & 3.286 & 67.58 & 2,860 \\
\hline & 87.5 & 1 & 14.4 & & & 67.09 & \\
\hline & 87.0 & 1 & 4.04 & 139 & 3.323 & 67.37 & 2,820 \\
\hline & 86.9 & 1 & 4.52 & & & 66.94 & \\
\hline & 86.8 & 1 & 2.32 & 138 & 3.140 & 65.43 & 2,880 \\
\hline & 86.5 & 1 & 1.95 & & & 65.51 & \\
\hline & 86.3 & 1 & 2.31 & 142 & 3.166 & 65.84 & 2,950 \\
\hline & 86.0 & 1 & 1.47 & & & 64.95 & \\
\hline & 85.4 & 1 & 3.17 & 144 & 3.267 & 65.24 & 2,880 \\
\hline & 85.6 & 1 & 2.59 & 141 & 3.190 & 64.96 & 2,870 \\
\hline 19 & 85.8 & 245 & 14.4 & 145 & 3.116 & 65.33 & 3,040 \\
\hline 20 & 86.0 & 228 & 157 & 140 & 2.786 & 62.51 & 3,140 \\
\hline 21 & 86.5 & 218 & 204 & 144 & 2.674 & 58.47 & 3,150 \\
\hline 22 & 85.8 & 238 & 252 & 141 & 2.429 & 54.82 & 3,180 \\
\hline 23 & 85.5 & 229 & 235 & 141 & 2.279 & 50.51 & 3,130 \\
\hline 24 & 84.6 & 240 & 302 & 141 & 2.169 & 45.96 & 2,990 \\
\hline 25 & 84.8 & 257 & 186 & 142 & 2.029 & 43.72 & 3,060 \\
\hline 26 & 84.4 & 236 & 240 & 141 & 1.904 & 40.73 & 3,020 \\
\hline 27 & 84.3 & ad lib & 132 & & & 38.31 & \\
\hline 28 & 84.0 & ad lib & 91.2 & 140 & 1.763 & 37.01 & 2,940 \\
\hline 29 & 84.8 & ad lib & 113 & & & 35.83 & \\
\hline 30 & 84.6 & ad lib & 55 & 139 & 1.682 & 35.13 & 2,900 \\
\hline 31 & & ad lib & 113 & & & & \\
\hline 32 & & ad lib & 181 & & & & \\
\hline 33 & & ad lib & 174 & & & & \\
\hline 34 & 85.8 & ad lib & 202 & 141 & 1.277 & 28.31 & 3,130 \\
\hline 35 & 84.8 & ad lib & 248 & & & 26.27 & \\
\hline 36 & 84.4 & ad lib & 177 & 138 & 1.179 & 24.55 & 2,870 \\
\hline 37 & 84.3 & ad lib & 95.1 & & & 24.15 & \\
\hline 38 & 84.9 & ad lib & 82.5 & 142 & 1.051 & 23.56 & 3,180 \\
\hline
\end{tabular}

TABLE III

Changes in serum sodium concentration and exchangeable sodium with increased sodium intake

\begin{tabular}{|c|c|c|c|c|c|c|c|c|}
\hline \multirow[b]{2}{*}{ Subject } & \multicolumn{3}{|c|}{ Low-sodium period } & \multicolumn{5}{|c|}{ High-sodium period } \\
\hline & $\begin{array}{c}\mathrm{Na} \\
\text { intake }\end{array}$ & $\begin{array}{l}\text { Serum Na } \\
\quad \pm \mathrm{SD}\end{array}$ & $\mathrm{Na}_{\mathrm{e}} \pm \mathrm{SD}$ & $\begin{array}{c}\mathrm{Na} \\
\text { intake }\end{array}$ & $\begin{array}{l}\text { Serum Na } \\
\quad \pm S D\end{array}$ & $\mathrm{Na}_{\mathrm{e}} \pm \mathrm{SD}$ & $\underset{\mathrm{Na}^{*}}{\Delta \text { Serum }}$ & $\Delta \mathrm{Nae} \dagger$ \\
\hline & $m E q$ & $m E q / L$ & $m E q$ & $m E q$ & $m E q / L$ & $m E q$ & $m E q / L$ & $m E q$ \\
\hline L.M. & 20 & ${ }_{[9] \ddagger}+141.92$ & $\underset{[9]}{3,247} 29.2$ & 181 & $\underset{[7]}{145.0} 2.77$ & $3,481 \underset{[7]}{ \pm} 34.0$ & +3.1 & +234 \\
\hline B.E. & 20 & $\underset{[8]}{140.9 \pm 1.25}$ & $\underset{[8]}{2,635} \mathbf{3 2 . 6}$ & 358 & $\underset{[8]}{140.5}=1.69$ & $\underset{[8]}{2,830 \pm} 30.0$ & -0.4 & +195 \\
\hline B. B. & 1 & $140.1 \underset{[7]}{ \pm} 1.58$ & $\underset{[6] \AA}{3,452}=140$ & 200 & $\underset{[5]}{138.8} \underset{[5]}{ \pm} 1.64$ & $\underset{[5]}{3,616 \pm} 107$ & -1.3 & +164 \\
\hline J.C. & 2 & ${ }_{[6]}^{140.5 \pm 2.28}$ & $\underset{[6]}{2,876 \pm} 27.9$ & 236 & $\underset{[8]}{141.8 \pm 1.73}$ & $\underset{[8]}{3,089 \pm 25.2}$ & +1.3 & +213 \\
\hline P.J. & 1 & $\underset{[14]}{138.1 \pm 1.73}$ & $\underset{[8]}{3,081 \pm 57.7}$ & 200 & $\underset{[6]}{145.8 \pm 1.21}$ & $\underset{[6]}{3,543 \underset{[6]}{ \pm}}$ & +7.7 & +462 \\
\hline
\end{tabular}

* Group change is insignificant (p greater than 0.2 ), according to paired $t$ test (12).

$\dagger$ Group difference significant ( $p$ less than 0.01 ).

Exchangeable sodium value for first day omitted from calculated mean. 


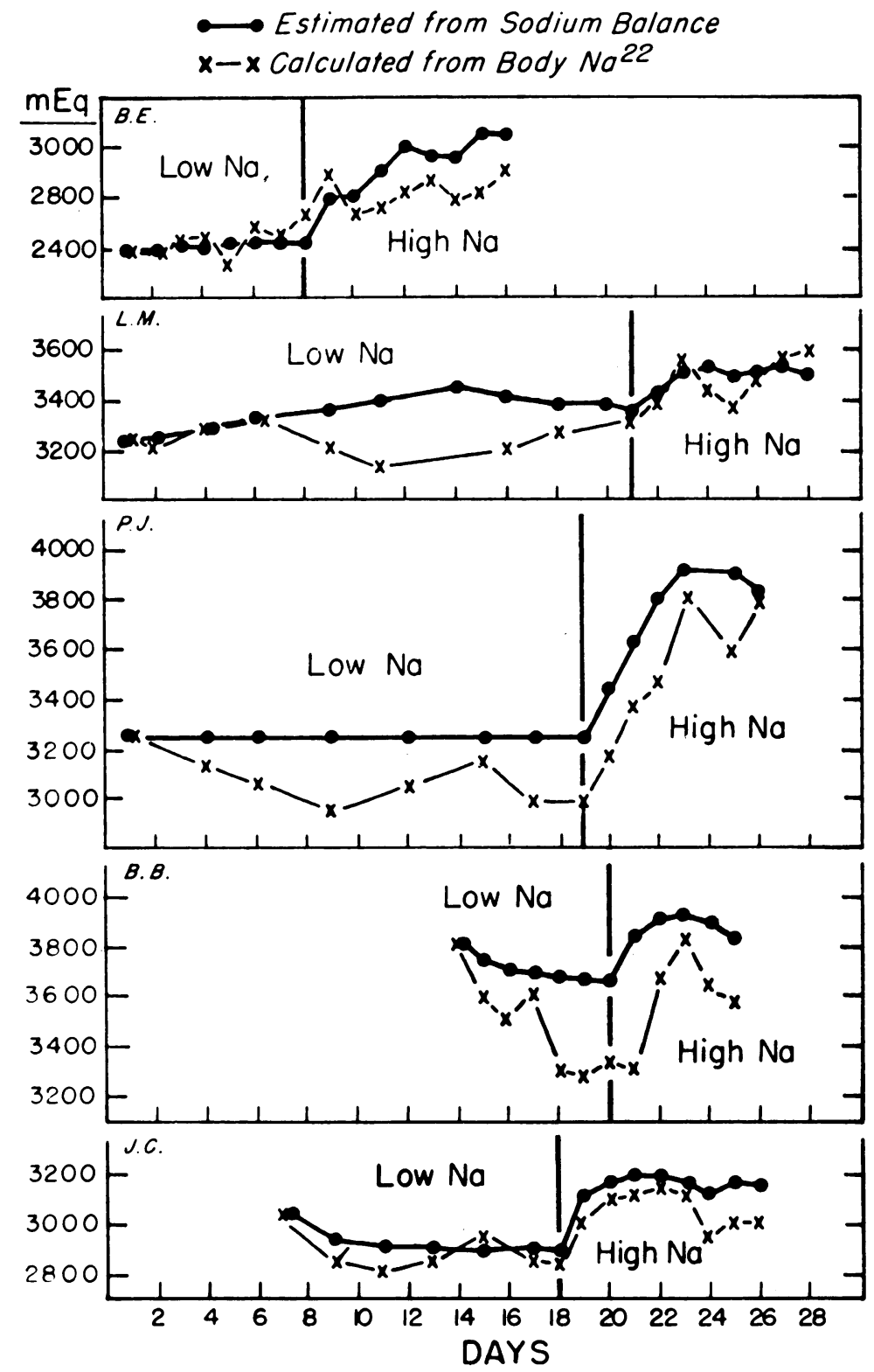

Fig. 3. Exchangeable sodium values Calculated from SERUM SPECIFIC ACTIVITY AND BODY-COUNTING DATA COMPARED WITH THOSE ESTIMATED FROM SODIUM BALANCE. The latter values were obtained from the value calculated for exchangeable sodium at the end of the first day of low-sodium intake, corrected for each subsequent day for the sodium balance determined from intake and urinary excretion.

subjects (L.M., P.J., and J.C.) and greater than the fixed high-sodium intake averages in the other two subjects (B.E. and B.B.).

Body weights. There were no significant changes in body weights for the group as a whole in going from low-sodium periods to high-sodium periods, perhaps because caloric intake was not regulated to energy requirements. Two subjects, in fact, were placed on low-calorie diets because they wished to lose weight. However, body weights usually decreased when the subjects were placed on fixed low-sodium diets and usually in- 
creased when they were changed to fixed highsodium diets. It is worth noting that the two subjects on low-calorie diets lost totals of $3.5 \mathrm{~kg}$ (P.J.) and $5.3 \mathrm{~kg}$ (J.C.) without a significant difference in exchangeable sodium at the beginning and end of the studies.

Serum sodium concentration. The increase in serum sodium concentration for the group in going from a low-sodium intake to a high-sodium intake was not significant (Table III). The three subjects (P.J., L.M., and J.C.) who showed an increase in serum sodium concentration also showed the greatest increase in average exchangeable sodium between the low-sodium and highsodium periods. The calculated values for exchangeable sodium are dependent on the serum sodium values, but the validity of these observa- tions is supported by the fact that these subjects had been on the low-sodium diets for the longest intervals (11 or more days) before changing to a high-sodium intake.

Sodium balance. Daily 24-hour urine sodium excretions fell gradually to low levels, remained relatively constant when the subjects were placed on fixed low-sodium diets, and then gradually increased again after the institution of the fixed high-sodium intakes. A negative sodium balance, as determined from the urinary excretion, tended to coincide with a fall in measured exchangeable sodium, while a positive balance coincided with an increase.

A curve of estimated exchangeable sodium values can be constructed for the periods of fixed sodium intake by beginning with the value for

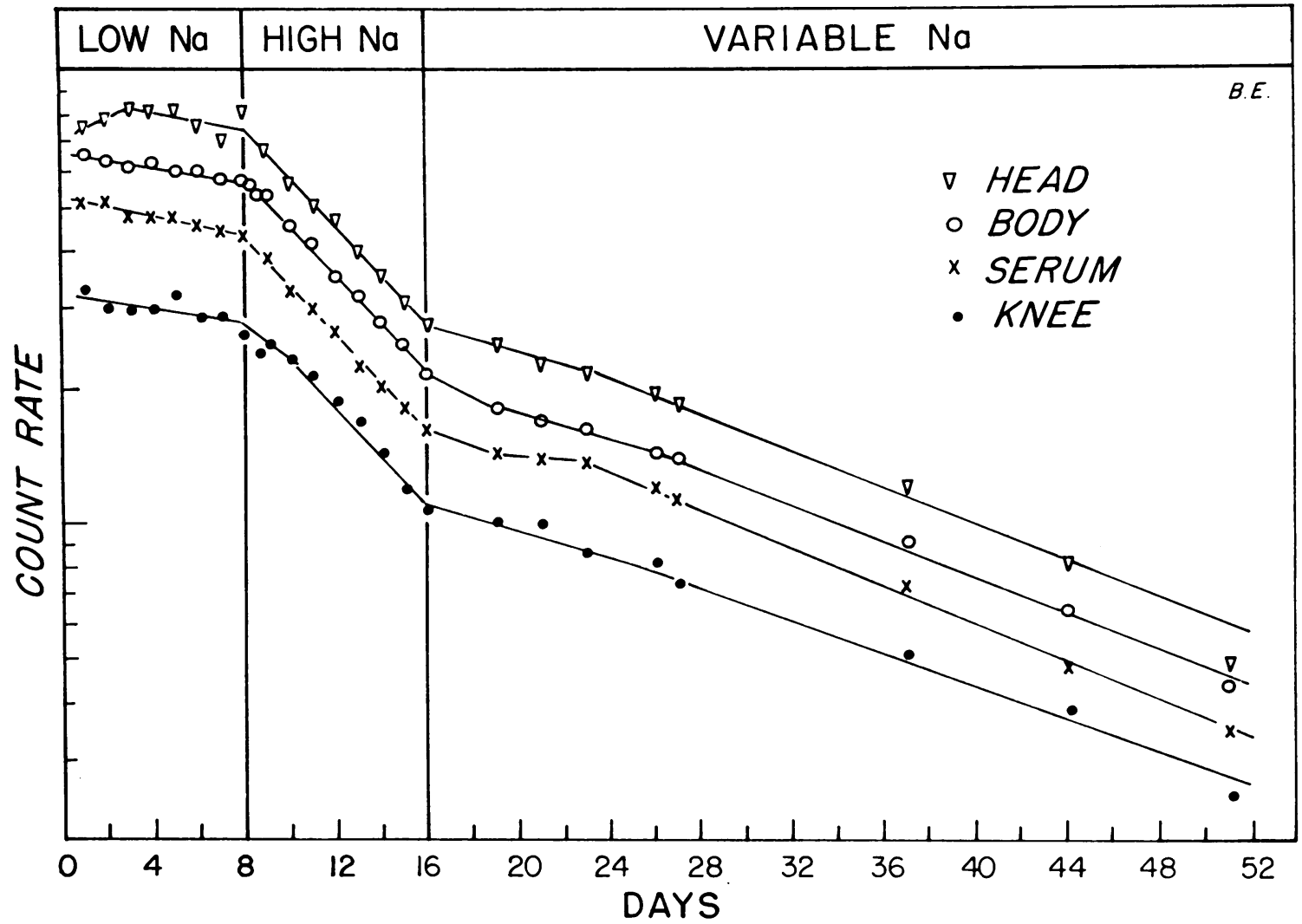

Fig. 4. Representative Set of Radioactivity measurements ObTAINed by the body COUNTER AND By COUNTERS CLOSE TO THE HEAD AND THE KNEE. The curve of serum radioactivity is also included. The count rates are plotted on a logarithmic scale against time; the actual count rates were multiplied or divided by some arbitrary factors to bring all curves close together for better comparison. This example shows the prolonged equilibration time of the head, but not that of the knee as seen in other cases; it was chosen because of the long follow-up (51 days). After the initial period of equilibration, the curves are roughly parallel throughout. There is no evidence for continued slow penetration of $\mathrm{Na}^{22}$ into the bone of knee or head. 


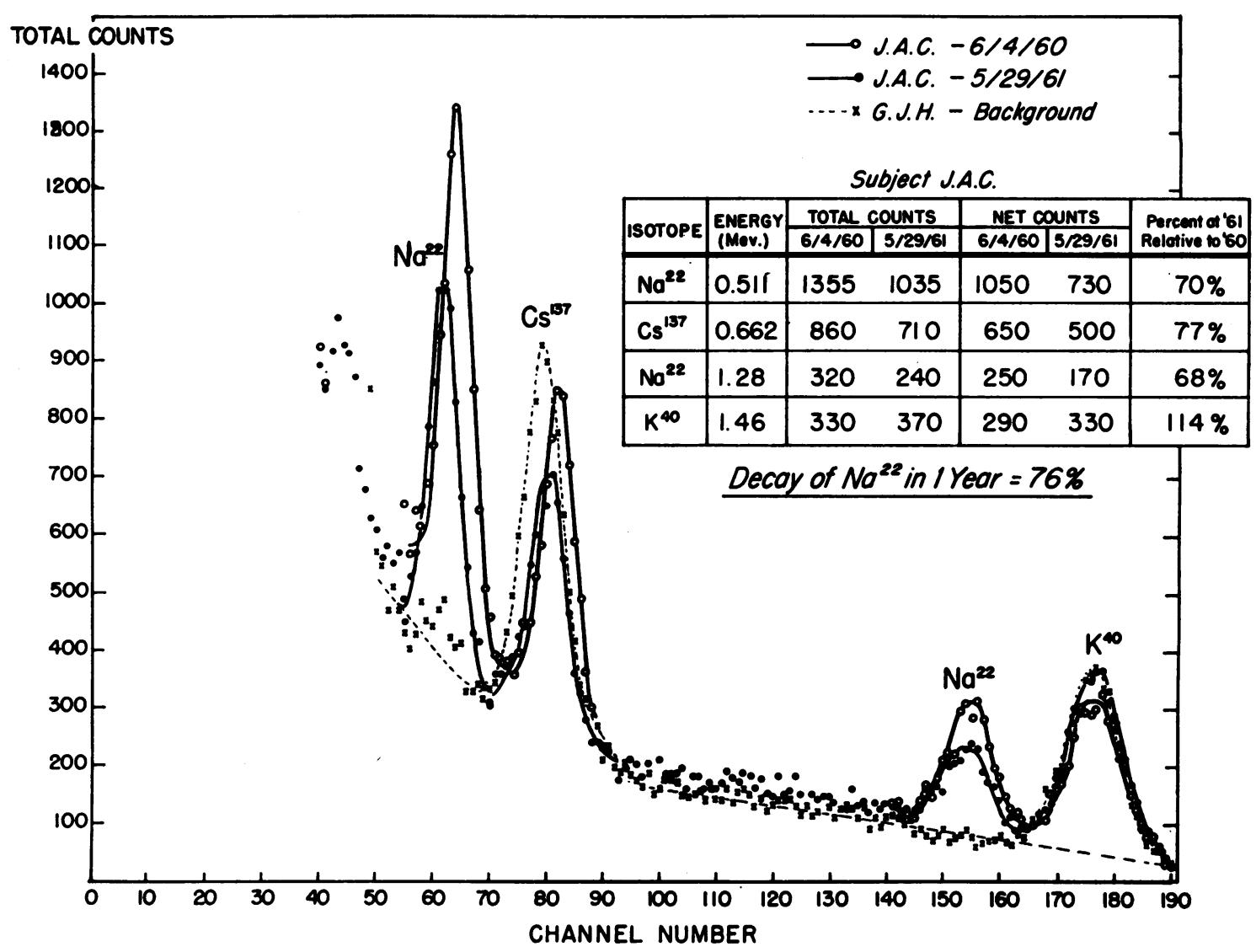

Fig. 5. GAMma-RAy SPECTRA OBTAINEd IN IRON ROOM AT 15 AND 27 MONTHS AFTER AdMinistration OF TRACER DoSE OF $\mathrm{NA}^{22}$ To Subject J.C. Measurements of body radioactivity of Subject G.J.H., who had not received $\mathrm{Na}^{22}$, were obtained to serve as body background radioactivity in areas of $\mathrm{Na}^{22}$ photopeaks. The $1.28 \mathrm{Mev} \mathrm{Na}^{22}$ peak activity was approximately one-half that of the $1.46 \mathrm{Mev} \mathrm{K}^{40}$ peak activity on 6/4/60. Also shown are the 0.511 $\mathrm{Mev} \mathrm{Na}^{22}$ photopeak and an adventitious $0.622 \mathrm{Mev} \mathrm{Cs}^{137}$ photopeak. With the $\mathrm{K}^{40}$ photopeak as a standard, the decrease in $\mathrm{Na}^{22}$ photopeak activities during the following year was approximately one-third.

calculated exchangeable sodium at the end of the first day of fixed intake and then correcting on each subsequent day for the sodium balance as determined from intake and urinary excretion. In Figure 3, the curve determined by the above method and the curve calculated from serum specific activity and body radioactivity are shown for each of the subjects. The curves show similar trends in each case; however, there is more variation in the day-to-day values calculated from serum specific activity and body radioactivity, and these values are usually lower than the balance values for the same day.

Head and knee radioactivity measurements. Figure 4 shows a representative set of curves for radioactivity as recorded by the body counter and by the counters at the head and at the knee, together with the curve for serum radioactivity. As might be anticipated, times for equilibration of the $\mathrm{Na}^{22}$ recorded by the counters at the head in this subject and in both the head and knee in others are prolonged as compared with the time for equilibrium recorded by the body counter and in the serum samples. After equilibration, however, all the curves are parallel throughout the rest of the study periods.

$N a^{24}$ study. On day 71 of the study in subject B.E., an exchangeable sodium value was determined from the $\mathrm{Na}^{22}$ data in the usual manner. A tracer dose of $\mathrm{Na}^{24}$ was then administered intravenously, and urine was collected for the next 24 hours while the patient took approxi- 
TABLE IV

Peak ratios of $N a^{22}$ relative to $K^{40 *}$

\begin{tabular}{ccccc}
\hline \hline \multirow{2}{*}{ Subject } & $\begin{array}{c}\mathrm{Na}^{22} \\
\text { gamma } \\
\text { rays }\end{array}$ & \multicolumn{3}{c}{ Date of measurement } \\
\cline { 3 - 5 } & Mev & $\%$ & $\%$ & $\%$ \\
J.C. & 0.51 & 100 & 61 & 42 \\
& 1.28 & 100 & 60 & 40 \\
P.J. & 0.51 & 100 & 55 & 50 \\
& 1.28 & 100 & 63 & 39 \\
B.B. & 0.51 & 100 & 58 & 33 \\
& 1.28 & 100 & 41 & 31
\end{tabular}

* $\mathrm{Na}^{22}$ to $\mathrm{K}^{40}$ ratios are given for both $\mathrm{Na}^{22}$ annihilation radiation $(0.51 \mathrm{Mev})$ and for the $\mathrm{Na}^{22}$ gamma ray $(1.28 \mathrm{Mev})$. The average of all data yields an effective half-life of about 1.3 years. Correcting for physical half-life (2.6 years) yields a biological half-life of approximately 2.6 years. At 15 to 19 months after the tracer doses of $\mathrm{Na}^{22}$, heights of the $\mathrm{Na}^{22} 1.28 \mathrm{Mev}$ photopeak and the $\mathrm{K}^{40} 1.46 \mathrm{Mev}$ photopeak in the gamma-ray spectra were approximately the same in all subjects. If we assume a body burden for $\mathrm{K}^{40}$ of $0.12 \mu \mathrm{c}$ and a gamma-ray abundance for $\mathrm{Na}^{22}$ ten times that for $\mathrm{K}^{40}$, this indicated a retention of ap proximately $0.1 \%$ of the initial dose of $\mathrm{Na}^{22}$. The ratio of the $\mathrm{Na}^{22}$ photopeaks to the $\mathrm{K}^{40}$ photopeak on $6 / 4 / 60$ was taken as $100 \%$ fo comparison with the $\mathrm{Na}^{22}: \mathrm{K}^{40}$ photopeak ratios obtained at yearly intervals thereafter.

mately the same diet as during the previous day. At the end of the 24 hours, an exchangeable sodium value was determined from the serum specific activity of $\mathrm{Na}^{24}$ and body retention of that isotope, as indicated by urine data. The exchangeable sodium value determined from $\mathrm{Na}^{22}$ 71 days after its administration was $2,920 \mathrm{mEq}$, and the value determined the next day from $\mathrm{Na}^{24}$, just 24 hours after its administration, was 2,910 $\mathrm{mEq}$.

Long-term $\mathrm{Na}^{22}$ retention. Initial measurements in the steel counting-room were made 15 to 19 months after injection of the $\mathrm{Na}^{22}$ doses. The gamma-ray spectra that were obtained at this time showed a retention of $\mathrm{Na}^{22}$ that was less than the naturally occurring $\mathrm{K}^{40}$ in all three subjects. Subsequent determinations expressed as percentages of this initial $\mathrm{Na}^{22}: \mathrm{K}^{40}$ ratio showed a markedly prolonged biological half-time, averaging approximately 2.6 years, as compared to an 11- to 15-day half-time for fall-off of serum $\mathrm{Na}^{22}$ activity in the same patients on their normal diets (Figure 5, Table IV).

\section{DISCUSSION}

Several lines of evidence bear upon the question of whether or not there is a later significant penetration of the $\mathrm{Na}^{22}$ tracer into that fraction of body sodium that has not equilibrated in the first 24 to 48 hours. The first is found in the curves for exchangeable sodium in the three subjects who began their studies on fixed low-sodium diets. There is some variability in day-to-day values for exchangeable sodium, but for periods of 8 to 21 days. there is no definite trend toward an increase in values that would occur with continuing penetration of $\mathrm{Na}^{2:-2}$ into a slowly exchanging sodium space.

The second line of evidence comes from the comparison of curves of $\mathrm{Na}^{22}$ radioactivity fall-off recorded at the knee and at the back of the head with the curve for fall-off recorded by the body radioactivity counter and with the curve for serum $\mathrm{Na}^{22}$ radioactivity fall-off. The radioactivity at knee and head increases for 24 to 48 hours after body and serum curves have leveled off, but after this the curves are parallel. If there were significant further exchange of the $\mathrm{Na}^{22}$ with the sodium in bone after the first few days, the curves at knee and head should have had a slower rate of fall-off during the rest of the study than the curves for body and serum. This failure to show further exchange is comparable to the work in dogs reported by Edelman, James, Baden, and Moore (9), who compared bone specific activities to serum specific activities, and found that approximately $45 \%$ of the bone sodium was readily exchangeable in the first 1 to 3 days and that the rest showed no tendency to exchange over the next 30 days.

The third line of evidence comes from inspection of the curves for exchangeable sodium predicted from balance data and the curves calculated from serum specific activity and body radioactivity (Figure 3 ). Continuing exchange of the tracer should result in calculated exchangeable sodium values increasingly larger than those estimated from the balance data; however, this is apparently not the case. Still further evidence comes from the comparison of the exchangeable sodium value calculated from the $\mathrm{Na}^{22}$ data on day 71 of the study in B.E. with the 24-hour value for exchangeable sodium calculated from the $\mathrm{Na}^{24}$ data on the next day. If there had been a continuing slow exchange of the $\mathrm{Na}^{22}$ over the previous 71 days, the exchangeable sodium value calculated from the $\mathrm{Na}^{22}$ should have been significantly greater than that calculated from the $\mathrm{Na}^{24}$, but the values were almost identical. Similarly close correlations were obtained between exchangeable sodium calculated from $\mathrm{Na}^{22}$ on day 
98 and from $\mathrm{Na}^{24}$ on day 99 in one edematous subject and on days 100 and 101 in another (13).

Other reports have indicated results contrary to the above, with exchangeable sodium values, or with sodium spaces continuing to increase for a period of a week or more $(1,4-7)$. In the studies that did not employ direct measurements of body radioactivity (4-6), these contradictory results can probably be attributed to incomplete assessment of body $\mathrm{Na}^{22}$ losses, either because of failure to measure extrarenal losses or because of incomplete collections. This would result in values for body $\mathrm{Na}^{22}$ retention progressively higher than the actual retention, and use of these in the calculation of exchangeable sodium would result in values for exchangeable sodium that are increasingly larger than the actual values. The studies that did employ measurements of body radioactivity differ from the present one in that the subjects were not placed on fixed sodium intakes. As discussed below, exchangeable sodium varies according to sodium intake, and therefore it is difficult to draw definitive conclusions from studies in which sodium intake was not controlled.

While continuing penetration of the $\mathrm{Na}^{22}$ tracer into a very slowly exchanging space does not significantly affect determinations of exchangeable sodium, measurements of body radioactivity over long intervals indicate that slow penetration of minute amounts of $\mathrm{Na}^{22}$ does occur. Measurements in the steel room indicate the persistence in the body of greater quantities of $\mathrm{Na}^{22}$ than would be expected from extrapolation of the disappearance slopes of serum radioactivity while the subjects were on normal diets; this persisting $\mathrm{Na}^{22}$ has a disappearance half-time measured in years, rather than in days. This prolonged retention of minute amounts of $\mathrm{Na}^{22}$ by human subjects also has been demonstrated by others (14-16). This very slowly exchanging sodium probably represents the incorporation of sodium into the internal structure of bone crystals, at a rate dependent upon the normal continuing process of bone resorption and deposition (17, 18). That part of bone sodium that exchanges within 24 hours, on the other hand, probably is the sodium that is merely absorbed on bone crystal surfaces $(15,17,19,20)$, or that displaces calcium ions from the surfaces of the crystal lattice.
The 24-hour equilibration time used in this present study in normal individuals may not always be adequate for patients with certain disease states. Such patients may well require 48 hours, 72 hours, or even slightly longer for equilibration $(2,21,22)$. In a group of edematous patients in whom 48 hours was allowed for equilibration, evidence similar to that in normal subjects for lack of significant continuing exchange after this initial equilibration period was obtained $(13,23)$.

The mean values for exchangeable sodium during the periods of high-sodium intake were significantly higher for the group than the mean values during the low-sodium periods (Table III), even though final equilibrium following the change in sodium intake might not have been obtained. In three of the subjects, the agreement between the increase in sodium intake and the increase in exchangeable sodium was within 100 $\mathrm{mEq}$. In one subject, B.E., who had some diarrhea during the period of high-sodium intake, the increase in sodium intake exceeded the mean increase in exchangeable sodium by $143 \mathrm{mEq}$, and in one subject, P.J., who was on a low-sodium intake before the high-sodium period for the longest interval, the increase in mean exchangeable sodium exceeded the increase in daily sodium intake by $263 \mathrm{mEq}$. In four of the five subjects, the increase in exchangeable sodium with an increase in sodium intake was about $200 \mathrm{mEq}$. More studies with a wide range of sodium intakes would be needed to substantiate this point, but this may be evidence that homeostatic mechanisms allow for relatively fixed net changes in exchangeable sodium and that, for most normal subjects at least, in going from a low- to a high-sodium intake, these changes are around $200 \mathrm{mEq}$.

The increase in body sodium with increased sodium intake is also confirmed by balance data. The curves for exchangeable sodium estimated from balance data and the calculated curves show similar trends in each subject (Figure 3). As noted above, the day-to-day values calculated from radioactivity measurements show more variability and tend to be lower. The lower values, however, may be closer to the true values, particularly in the later days of the studies, in that measurements of body radioactivity account for losses of sodium by nonrenal routes that are missed by the balance method. It is true that stool sodium losses by 
one subject (P.J.) in whom collections were made totaled only $15 \mathrm{mEq}$ over a 26-day period, but greater sodium losses may have occurred in Subject B.E. to account for the divergence hetween the balance curve and the hody radioactivity curve during his period of high-sodium intake.

A change in exchangeable sodium with a change in sodium intake could be anticipated from previous studies (24). It is possible that the apparent magnitude of these changes may be due in part to incomplete mixing of the daily increments of stable sodium with the exchangeable sodium. This would give a falsely low serum specific activity which, in the subsequent calculations, would result in a falsely high exchangeable sodium. Equilibration of $\mathrm{Na}^{22}$ and $\mathrm{Na}^{2+}$ with serum sodium is reasonably complete within 12 to 24 hours $(10,21,25,26)$. If we can assume that equilibration of stable sodium follows the same time course, the practice of giving the sodium supplements during the first part of each study day should have minimized this effect of increased sodium intake on the estimations of exchangeable sodium.

The magnitude and the pattern of the rises in exchangeable sodium when high sodium intakes followed sodium deprivation were probably due in part to the increased levels of circulatory aldosterone resulting from sodium restriction (27-32). One may speculate that the increases in exchangeable sodium to peak values over several days followed by a fall-off to intermediate values seen in at least two of the studies (J.C. and B.B., Figure 4) are indicative of levels of circulatory aldosterone that result in an "overcompensation" for the previous sodium deficit; then, as the levels of aldosterone fall, the excess sodium is excreted. A similar cyclical pattern with sodium loading has previously been reported (31).

It is not possible from the present data to determine the relative contribution of different body compartments to the sodium lost in going from the regular to the fixed low-sodium diets, nor the distribution among body compartments of the sodium gained in going from the fixed low- to the fixed high-sodium diets. On the basis of reported animal studies, however, it can be predicted that the extracellular fluid compartment would show the greatest changes followed by the exchangeable fraction of bone sodium (32-37).

\section{SUMMARY}

1. Long-term studies of sodium metabolism in five normal subjects were carried out by use of tracer doses of $\mathrm{Na}^{22}$ and measurement of body radioactivity to make repeated exchangeable soclium determinations.

2. Body sodium exchanging after the first 24 to 48 hours was not a significant fraction of the metabolically active sodium pool, nor did it interfere with long-term measurements of this pool by isotope dilution methods.

3. Exchangeable sodium was shown to vary directly with changes in sodium intake.

4. A small fraction of the tracer doses of $\mathrm{Na}^{22}$ was shown to have a prolonged biological half-life consistent with its incorporation within bone crystals.

\section{REFERENCES}

1. Veall, N., H. J. Fisher, J. C. McC. Browne, and J. E. S. Bradley. An improved method for clinical studies of total exchangeable sodium using ${ }^{22} \mathrm{Na}$ and a whole-body counting technique. Lancet 1955, 1, 419.

2. Martin, M. M., G. Walker, and M. Chapman. Sodium balance studied with ${ }^{22} \mathrm{Na}$ and an external counter for measuring whole-body radioactivity. Lancet 1957, 1, 653.

3. Hine, G. J., P. I. Jagger, and B. A. Burrows. Measurement of body radioactivity for studies of sodium metabolism. J. Lab. clin. Med. 1960, 55, 476.

4. Streeten, D. H. P., A. Rapoport, and W. S. Wilson. The existence of a large, slowly-exchangeable pool of body sodium (abstract). J. clin. Invest. 1958, 37, 934.

5. Miller, H., D. S. Munro, H. E. Renschler, and G. M. Wilson. Observations on the measurement and distribution of exchangeable sodium in man in Proc. 2nd Radioisotope Conf., Oxford, 1954. New York, Academic Press, 1954, vol. 1, pp. 138146.

6. Dieckmann, W. J., and R. Pottinger. Total exchangeable sodium and space in normal and preeclamptic patients determined with sodium ${ }^{22}$. Amer. J. Obstet. Gynec. 1957, 74, 816.

7. Klein, L., and J. Carey. Total exchangeable sodium in the menstrual cycle. Amer. J. Obstet. Gynec. 1957, 74, 956.

8. Edelman, I. S., and J. Leibman. Anatomy of body water and electrolytes. Amer. J. Med. 1959, 27, 256.

9. Edelman, I. S., A. H. James, H. Baden, and F. D. Moore. Electrolyte composition of bone and the penetration of radiosodium and deuterium oxide 
into dog and human bone. J. clin. Invest. 1954, 33, 122.

10. Miller, H., and G. M. Wilson. The measurement of exchangeable sodium in man using the isotope ${ }^{24} \mathrm{Na}$. Clin. Sci. 1953, 12, 97.

11. Bergstrom, W. H. The skeleton as an electrolyte reservoir. Metabolism 1956, 5, 433.

12. Snedecor, G. W. Statistical Methods Applied to Experiments in Agriculture and Biology, 5th ed. Ames, Iowa State College Press, 1956, p. 52.

13. 'Hine, G. J., P. I. Jagger, and B. A. Burrows. Use of a clinical body counter for long-term exchangeable sodium studies in Whole-Body Counting. Vienna, International Atomic Energy Agency, 1962, pp. 413-426.

14. Miller, H., D. S. Munro, and G. M. Wilson. The human use of ${ }^{22} \mathrm{Na}$. Lancet 1957, 1, 734.

15. Richmond, C. R. Retention and excretion of radionuclides of the alkali metals by five mammalian species. Los Alamos Report 2207 (New Mex.) 1958.

16. Smilay, M. G., L. K. Dahl, S. C. Spraragen, and L. Silver. Isotopic sodium turnover studies in man: evidence of minimal sodium $\left(\mathrm{Na}^{22}\right)$ retention 6 to 11 months after administration. J. Lab. clin. Med. 1961, 58, 60.

17. Neuman, W. F., and M. W. Neuman. Emerging concepts of the structure and metabolic functions of bone. Amer. J. Med. 1957, 22, 123.

18. Harrison, H. E. The sodium content of bone and other calcified material. J. biol. Chem. 1937, 120, 457.

19. Nichols, G., Jr., and N. Nichols. The role of bone in sodium metabolism. Metabolism 1956, 5, 438.

20. Stoll, W. R., and W. F. Neuman. The uptake of sodium and potassium ions by hydrated hydroxyapatite. J. Amer. chem. Soc. 1956, 78, 1585

21. Martin, M. M., and G. Walker. Studies with $\mathrm{Na}^{22}-$ an assessment of sodium balance and distribution. Metabolism 1957, 6, 466.

22. Burch, G. E., C. T. Ray, and S. A. Threefoot. Estimation of the time of equilibrium of distribution of long-life radiochloride and radiosodium in man with and without chronic congestive heart failure. Acta med. scand. (suppl.) 1952, 266, 329.

23. Jagger, P., G. Hine, J. Cardarelli, and B. Burrows. Sodium $^{22}$ equilibrium and exchangeable sodium determinations in edematous patients. Clin. Res. 1960, 8, 229.
24. Strauss, M. B. Body Water in Man, the Acquisition and Maintenance of the Body Fluids. Boston, Little, Brown, 1957.

25. Forbes, G. B., and A. Perley. Estimation of total body sodium by isotopic dilution. I. Studies on young adults. J. clin. Invest. 1951, 30, 558.

26. Edelman, I. S., A. H. James, I. Brooks, and F. D. Moore. Body sodium and potassium. IV. The normal total exchangeable sodium: its measurement and magnitude. Metabolism 1954, 3, 530.

27. Crabbé, J., E. J. Ross, and G. W. Thorn. The significance of the secretion of aldosterone during dietary sodium deprivation in normal subjects. J. clin. Endocr. 1958, 18, 1159.

28. Duncan, L. E., Jr., G. W. Liddle, and F. C. Bartter. The effect of changes in body sodium on extracellular fluid volume and aldosterone and sodium excretion by normal and edematous men. J. clin. Invest. 1956, 35, 1299.

29. Bartter, F. C. The role of aldosterone in normal homeostasis and in certain disease states. Metabolism 1956, 5, 369.

30. Luetscher, J. A., Jr., and B. J. Axelrad. Increased aldosterone output during sodium deprivation in normal men. Proc. Soc. exp. Biol. (N. Y.) 1954, 87, 650 .

31. Baldwin, D., R. W. Alexander, and E. G. Warner, Jr. Chronic sodium chloride challenge studies in man. J. Lab. clin. Med. 1960, 55, 362.

32. Nichols, N., and G. Nichols, Jr. Effect of large loads of sodium on bone and soft tissue composition. Proc. Soc. exp. Biol. (N. Y.) 1957, 96, 835.

33. Nichols, G., Jr., and N. Nichols. Changes in tissue composition during acute sodium depletion. Amer. J. Physiol. 1956, 186, 383.

34. Bergstrom, W. H., and W. M. Wallace. Bone as a sodium and potassium reservoir. $\mathrm{J}$. clin. Invest. 1954, 33, 867.

35. Bergstrom, W. H. The participation of bone in total body sodium metabolism in the rat. $\mathrm{J}$. clin. Invest. 1955, 34, 997.

36. Woodbury, D. M. Effect of hyponatremia on distribution of water and electrolytes in various tissues of the rat. Amer. J. Physiol. 1956, 185, 281.

37. Munro, D. S., R. S. Satoskar, and G. M. Wilson. The exchange of bone sodium with isotopes in rats. J. Physiol. 1957, 139, 474. 